\title{
IL-18 polymorphisms and tuberculosis susceptibility: a meta-analysis
}

\author{
Li-Bo Zhen,Ya-Ping Sun, Yuan-Yuan Chen, Liang-Sheng Yin
}

Department of Tuberculosis, Hangzhou Red Cross Hospital, 208 East Road, Hangzhou Ring, Hangzhou, China.

\begin{abstract}
Objective: To investigate the association between IL-18 polymorphisms and Tuberculosis(TB).

Materials and methods: We searched PubMed and Embase databases, and conducted a meta-analysis using 4 models. Data were extracted from the studies by two independent reviewers. Statistical analysis was performed using STATA 12.0 software.

Results: Five qualified studies with a total of $1293 \mathrm{~TB}$ patients and 1724 controls were included.There was no significant association between the IL-18 -607C > A polymorphism and TB risk in the total population(AA vs CC: OR=1.27,95\% CI=0.82-1.96;CA vs CC:OR=1.06,95\% CI=0.89-1.26; Dominant model: OR $=1.09,95 \%$ CI $=0.83-1.43$; Recessive model:OR=1.23, 95\% $\mathrm{CI}=0.92-1.65)$. For IL-18 $-137 \mathrm{G}>\mathrm{C}$ polymorphism, lack of an association was also found(GG vs $\mathrm{CC}: \mathrm{OR}=1.42,95 \% \mathrm{CI}=0.78$ 2.58; GC vs CC:OR=1.16,95\% CI=0.62-2.16; Dominant model: $\mathrm{OR}=1.34,95 \% \mathrm{CI}=0.74-2.43$; Recessive $\operatorname{model}: \mathrm{OR}=0.96,95 \%$ $\mathrm{CI}=0.26-3.56)$.
\end{abstract}

Conclusion: The present meta-analysis found no evidence for IL-18 -607C $>$ A and $-137 \mathrm{G}>\mathrm{C}$ polymorphisms as risk factors for TB. Further large-scale and well-designed articles are still needed to validate this result.

Keywords: Hardy Tuberculosis, interleukin-18, meta-analysis.

DOI: https://dx.doi.org/10.4314/ahs.v19i1.2

Cite as: Zhen L-B, Sun Y-P, Chen Y-Y, Yin L-S. IL-18 polymorphisms and tuberculosis susceptibility: a meta-analysis. Afri Health Sci. 2019;19(1): 1311-1320. https://dx.doi.org/10.4314/abs.v19i1.2

\section{Introduction}

Tuberculosis (TB) is currently among the most important global health challenges. A global TB report estimated approximately 8.7 million cases worldwide, most are in Asia and Africa ${ }^{1}$. Approximately one-third of the world's population is thought to be affected by $M$. tuberculosis, however, a relatively large number of infected individuals exhibit no signs of the disease. Nevertheless, the remaining $10 \%$ of infected individuals develop active disease later in life ${ }^{2}$. As we all know, a series of factors lead to the risk of infection and disease progression, including malnutrition, smoking, diabetes, alcohol use, socioeconomic status and environmental pollution ${ }^{3}$. Several studies have focused on the relationship between genetic variations of several genes and susceptibility to $\mathrm{TB}^{4,5}$.

\section{Corresponding author: \\ Liang-Sheng Yin, \\ Department of Tuberculosis, \\ Hangzhou Red Cross Hospital, 208 East Road, \\ Hangzhou Ring,Hangzhou, China. \\ Email: yinliangshengmed@sina.com}

Interleukin-18 (IL-18), first defined as an interferongamma inducing factor (IGIF), is a novel cytokine belonging to the IL-1 family and plays a strategic role in inflammation and immune reactions ${ }^{6}$. IL-18 is primarily produced by macrophages, dendritic cells, keratinocytes, osteoblasts and intestinal epithelial cells ${ }^{7}$. The role of IL-18 has been actively studied in the pathogenesis of many disease,including cancers and digestive diseases ${ }^{8}$. Evidence from previous studies appears to support a significant role of IL-18 in TB infection and anti-tuberculosis immunity 9

The IL-18 gene is located on chromosome 11q22.2-q22.3, and contains several genetic polymorphisms, especially in the promoter region. The variations in IL-18 gene promoter have an impact on the production and activity of IL-18. IL-18 gene promoter -607C>A (rs1946518) and $-137 \mathrm{G}>\mathrm{C}$ (rs187238) polymorphisms are two of the most common single nucleotide polymorphisms ${ }^{10}$. Cloning and transcriptional analysis showed that these two polymorphisms changed the IL-18 expression levels. However, studies conducted to examine the potential contributions of IL-18 polymorphisms to TB susceptibility have produced contradictory results. 
Individual studies based on small sample sizes do not have enough statistical power to detect positive associations, and perhaps more importantly, to prove that there is no association. Thus contradictory published results may only reflect the low statistical power of individual studies. Therefore, we performed a meta-analysis of all the data published so far to establish statistical evidence of the association between IL-18 polymorphisms and the risk of TB.

\section{Materials and methods}

\section{Literature search and selection criteria}

Through the search for Embase, Pubmed, Cochrane Library, the Chinese BiologicalMedical database and the Chinese National Knowledge Infrastructure databases, the following terms were searched up to January 2018: "tuberculosis" OR "TB" in combination with "interleukin" OR "IL" OR “-607C>A" OR "-137G>C" and "polymorphism" OR "variant" OR "gene".References of retrieved articles or/and reviews were also manually screened to obtain additional relevant eligible studies. Data were independently retrieved by 2 investigators $(\mathrm{Li}-$ Bo Zhen and Ya-Ping Sun), and a consensus was reached on all items.

\section{Criteria for inclusion and exclusion}

The inclusion criteria were as follows:(1) case-control studies conducted to assess the association between the IL-18 gene polymorphism and the risk of TB;(2)sufficient genotype data presented to calculate the odds ratios (ORs) and 95\% confidence intervals (CIs); and (3) the search was not restricted by language and was conducted on human subjects. The exclusion criteria were as follows:(1)abstracts and reviews;(2) genotype frequency not reported; and (3) repeat or overlapping publications.

\section{Data extraction}

The following data were abstracted from each study: First author's name, year of publication, country of sample, nationality,number of patients and controls,genotyping of gene polymorphisms,and evidence of Hardy-Weinberg equilibrium (HWE), which are listed in Table 1.

\section{Statistical analysis}

For included articles, the HWE of genotypes in the controls was evaluated using the Pearson chi-squared test. The strength of the association between IL-18 polymorphisms and TB risk was measured by odds ratios (ORs) with 95\% confidence intervals (CIs) for homozygote comparison (T'T versus CC), heterozygote comparison (CT versus $\mathrm{CC}$ ), dominant model( $\mathrm{T}$ T $+\mathrm{C}$ T versus $\mathrm{CC}$ ) and the recessive model (TT versus $\mathrm{CT}+\mathrm{CC}$ ). The heterogeneity among these studies was checked by the I2 test. I2 $>50 \%$ indicated heterogeneity across studies, in which case the random effects model was used for meta-analysis, otherwise the fixed effects model was used. Furthermore,a single study involved in the meta-analysis was deleted each time to reflect the influence of the individual dataset on the pooled ORs.Publication bias was measured using Begg's test and Egger's tests. The STATA 12.0 software was performed in our study(Stata Corp, College Station, TX, USA) .

\section{Results}

There were 193 related articles in the primary search. Screening was carried out exactly according to the inclusion and exclusion criteria. Abstracts as well as the whole papers were further read carefully and then 188 literatures were excluded. Finally, 5 case-control studies were included ${ }^{11-15}$. There was a total of 3017 subjects in the 5 case-control studies, including 1293 TB cases and 1724 controls. A detailed flowchart of the research options is shown in Figure 1. All the literature were the case-control studies of IL-18 polymorphisms and TB susceptibility in Asians. The baseline characteristics of this meta-analysis included in this meta-analysis are summarized in Table 1. All included case-control studies were published in English from 2007 to 2017. 


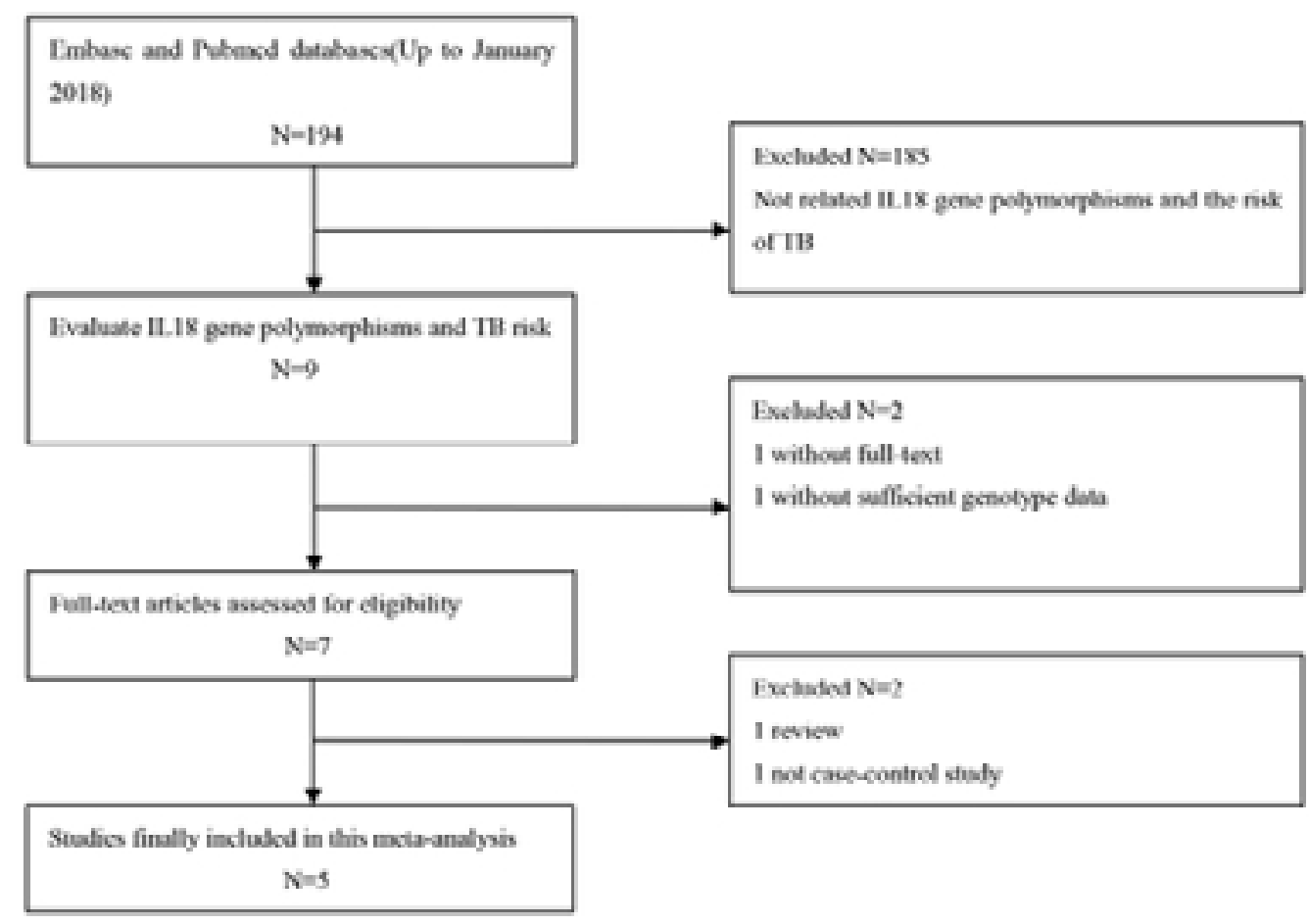

Figure 1: The flowchart of the included studies in the meta-analysis;

Table 1. Study selection and subject characteristics of included studies in meta-analysis.

\begin{tabular}{|c|c|c|c|c|c|c|c|c|c|c|c|c|}
\hline \multirow[t]{2}{*}{ Author } & \multirow[t]{2}{*}{ Year } & \multirow[t]{2}{*}{ Country } & \multirow[t]{2}{*}{ Ethnicity } & \multirow[t]{2}{*}{ cases } & \multirow[t]{2}{*}{ controls } & \multicolumn{3}{|c|}{$\begin{array}{l}\text { Genotypes for } \\
\text { cases }\end{array}$} & \multicolumn{3}{|c|}{$\begin{array}{l}\text { Genotypes for } \\
\text { controls }\end{array}$} & \multirow[t]{2}{*}{$\begin{array}{l}\text { P for } \\
\text { HWE }\end{array}$} \\
\hline & & & & & & $\mathbf{C C}$ & CA & $\mathbf{A A}$ & $\mathrm{CC}$ & $\mathbf{C A}$ & $\mathbf{A A}$ & \\
\hline \multicolumn{13}{|l|}{$-607 \mathrm{C}>\mathrm{A}$} \\
\hline Harishankar & 2007 & India & Asian & 165 & 173 & 75 & 71 & 19 & 85 & 73 & 15 & 0.90 \\
\hline Han & 2011 & China & Asian & 296 & 680 & 45 & 168 & 83 & 1643 & $395 \quad 1$ & 121 & 0.00 \\
\hline Lee & 2011 & Korea & Asian & 251 & 225 & 65 & 113 & 62 & 55 & 116 & 54 & 0.64 \\
\hline Taheri & 2012 & Iran & Asian & 174 & 177 & 74 & 80 & 20 & 68 & 90 & 19 & 0.18 \\
\hline Zhou & 2015 & China & Asian & 407 & 469 & 109 & 217 & 81 & 124 & 247 & 98 & 0.22 \\
\hline$-137 \mathrm{G}>\mathrm{C}$ & & & & & & GG & GC & $\mathrm{CC}$ & GG & GC & $\mathrm{CC}$ & \\
\hline Harishankar & 2006 & India & Asian & 165 & 173 & 97 & 51 & 10 & 103 & 56 & 9 & 0.70 \\
\hline Lee & 2011 & Korea & Asian & 251 & 225 & 188 & 61 & 2 & 173 & 47 & 5 & 0.40 \\
\hline Zhou & 2015 & China & Asian & 407 & 469 & 322 & 78 & 7 & 325 & 131 & 13 & 0.96 \\
\hline
\end{tabular}

The main results of meta-analysis of IL-18 -607C $>$ A polymorphism and TB risk are presented in Table 2.In pooled analysis using data from all 5 studies, no significant association was found between IL-18 -607C $>$ A polymorphism and TB risk(see Figure 2: AA vs CC: $\mathrm{OR}=1.27,95 \%$ $\mathrm{CI}=0.82-1.96 ; \mathrm{CA}$ vs $\mathrm{CC}: \mathrm{OR}=1.06,95 \% \quad \mathrm{CI}=0.89-1.26$;
Dominant model: OR $=1.09,95 \%$ CI $=0.83-1.43$;Recessive model:OR=1.23, 95\% CI=0.92-1.65). To explore the sources of heterogeneity, we performed further subgroup analyses by omission of non-HWE studies and the heterogeneity were removed, suggesting that the study deviating from HWE was the main source of heterogeneity in the meta analysis(Table 2). 


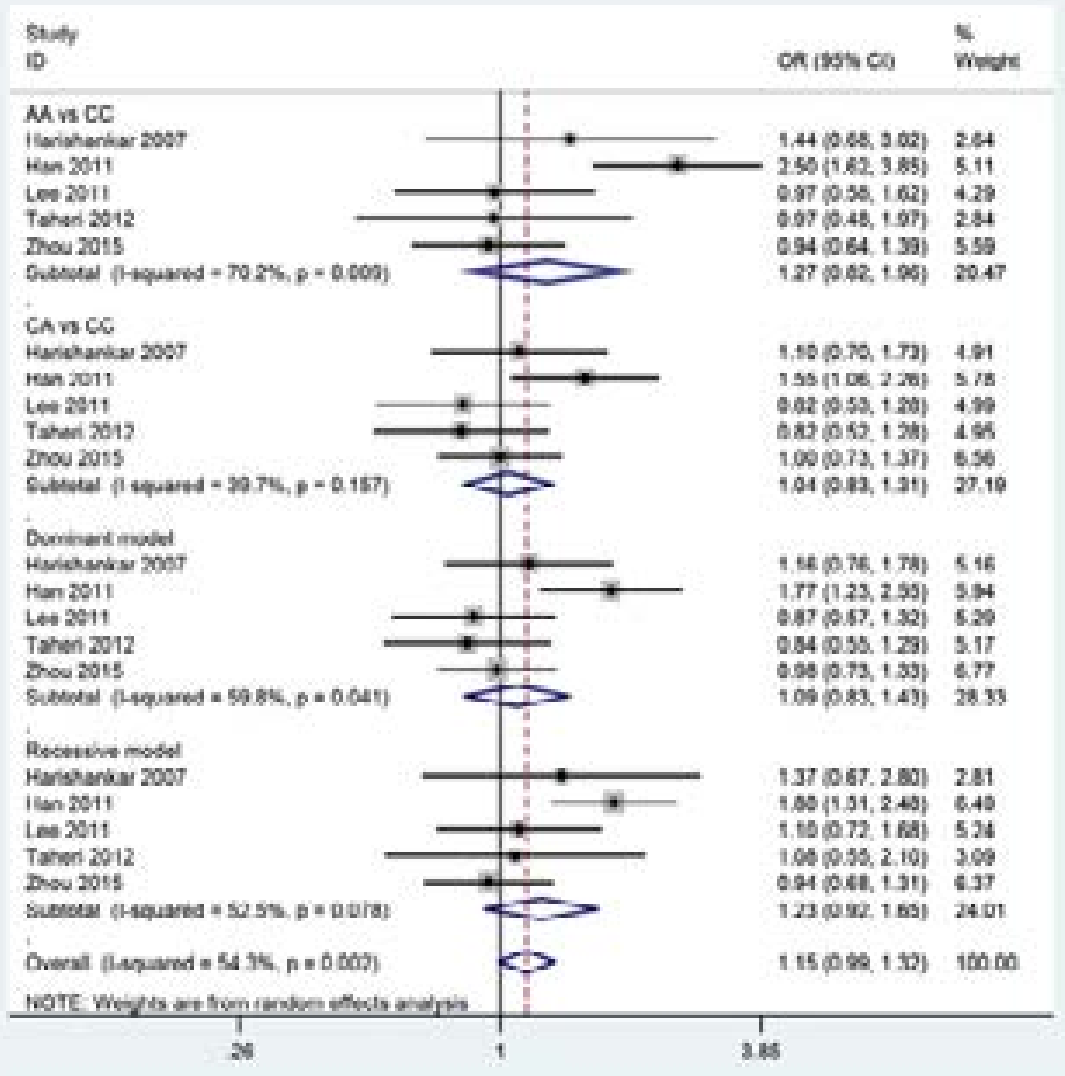

Figure 2: Forest plot for meta-analysis of the association between the IL-18 -607C $>$ A polymorphism and TB risk;

Table 2. Summary ORs and 95\%CI of IL-18 gene polymorphisms and TB risk.

\begin{tabular}{|c|c|c|c|c|c|c|}
\hline \multirow[t]{2}{*}{ Subgroup } & \multirow[t]{2}{*}{ Genetic model } & \multirow{2}{*}{$\begin{array}{l}\text { Effects } \\
\text { model }\end{array}$} & \multicolumn{2}{|c|}{ Test of heterogeneity } & \multicolumn{2}{|c|}{ Test of association } \\
\hline & & & $I^{2}$ & $P$ & OR & $95 \%$ CI \\
\hline \multicolumn{7}{|l|}{$-607 C>A$} \\
\hline \multirow[t]{4}{*}{ Overall } & $\mathrm{AA}$ vs $\mathrm{CC}$ & Random & $70.2 \%$ & 0.01 & 1.27 & $0.82-1.96$ \\
\hline & CA vs CC & Fixed & $39.7 \%$ & 0.16 & 1.06 & $0.89-1.26$ \\
\hline & Dominant model & Random & $59.8 \%$ & 0.04 & 1.09 & $0.83-1.43$ \\
\hline & Recessive model & Random & $52.5 \%$ & 0.08 & 1.23 & $0.92-1.65$ \\
\hline Consistent with & AA vs CC & Fixed & $0.00 \%$ & 0.80 & 1.01 & $0.77-1.31$ \\
\hline \multirow[t]{3}{*}{ HWE } & $\mathrm{CA}$ vs $\mathrm{CC}$ & Fixed & $0.00 \%$ & 0.72 & 0.94 & $0.77-1.15$ \\
\hline & Dominant model & Fixed & $0.00 \%$ & 0.72 & 0.96 & $0.79-1.16$ \\
\hline & Recessive model & Fixed & $0.00 \%$ & 0.80 & 1.04 & $0.83-1.31$ \\
\hline \multicolumn{6}{|l|}{$-137 \mathrm{G}>\mathrm{C}$} & $0.78-2.58$ \\
\hline & GC vs CC & Fixed & $0.00 \%$ & 0.38 & 1.16 & $0.62-2.16$ \\
\hline & Dominant model & Fixed & $0.00 \%$ & 0.38 & 1.34 & $0.74-2.43$ \\
\hline & Recessive model & Random & $78.4 \%$ & 0.03 & 0.96 & $0.26-3.56$ \\
\hline
\end{tabular}


The main results of meta-analysis of IL-18 $-137 \mathrm{G}>\mathrm{C}$ polymorphism and TB risk are summarized in Table 2.The results of pooling all studies showed that the IL-18 $-137 \mathrm{G}>\mathrm{C}$ polymorphism was not associ- ated with TB susceptibility (see Figure 3: GG vs CC: $\mathrm{OR}=1.42,95 \% \quad \mathrm{CI}=0.78-2.58 ; \mathrm{GC}$ vs $\mathrm{CC}: \mathrm{OR}=1.16,95 \%$ $\mathrm{CI}=0.62-2.16$; Dominant model: $\mathrm{OR}=1.34,95 \% \mathrm{CI}$ $=0.74-2.43$; Recessive model: $\mathrm{OR}=0.96,95 \% \mathrm{CI}=0.26$ $3.56)$.

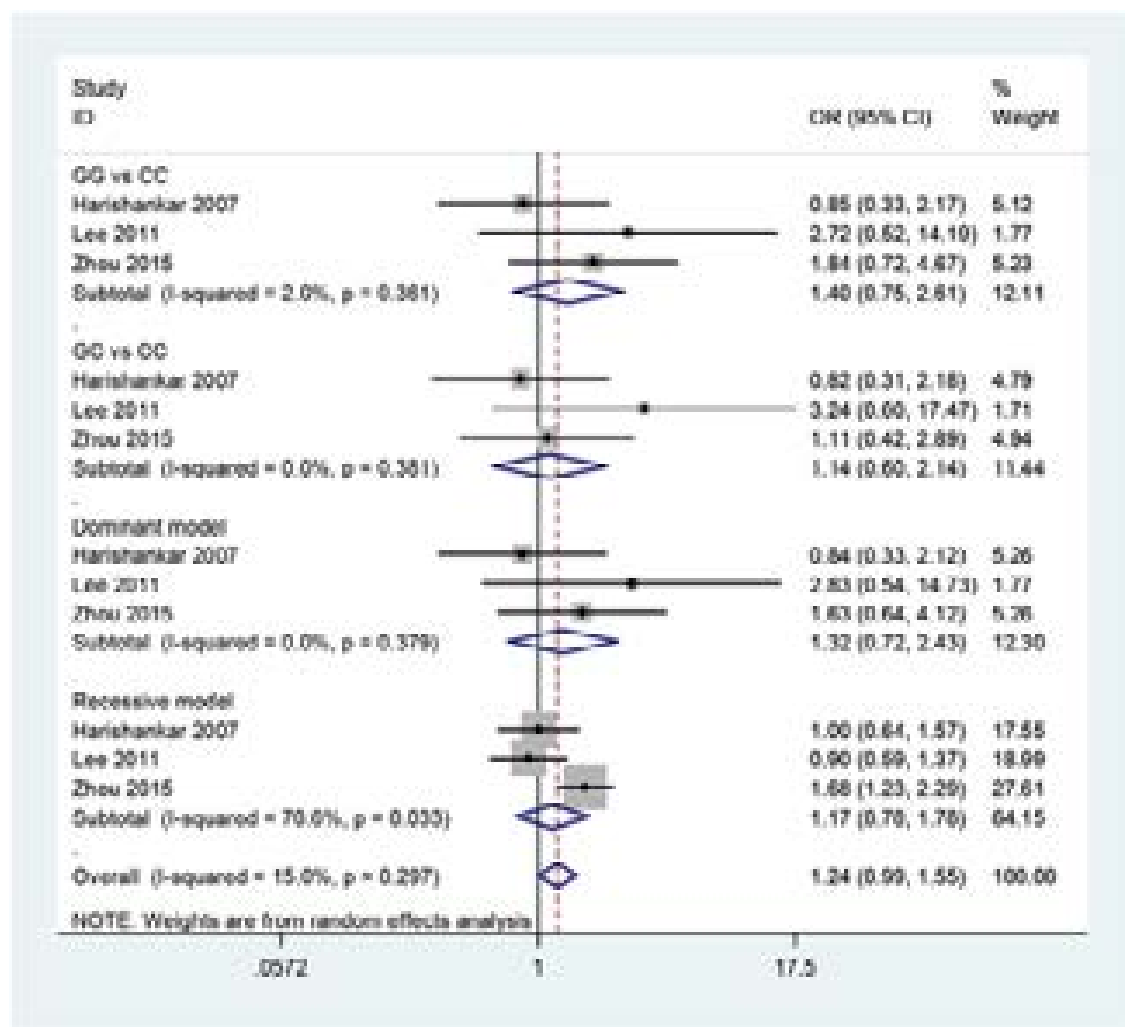

Figure 3: Forest plot formeta-analysis of the association between the IL-18-137G>C polymorphism and TB risk.

Sensitivity analysis was performed via assessment of the influence of each individual paper on the pooled OR by deleting one study at a time. No single article influenced the pooled ORs, suggesting that the results were stable (Figure 4 and 5). 


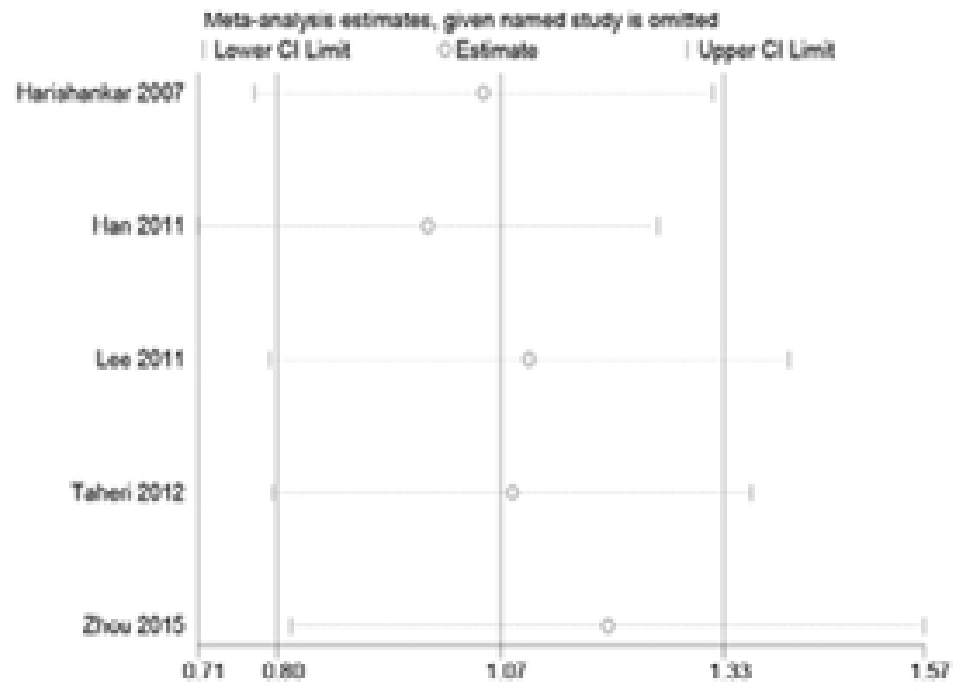

Figure 4: One-way sensitivity analysis of the pooled odds ratios and 95\% confidence interval for IL-18-607C $>$ A polymorphism, omitting each dataset in the meta-analysis

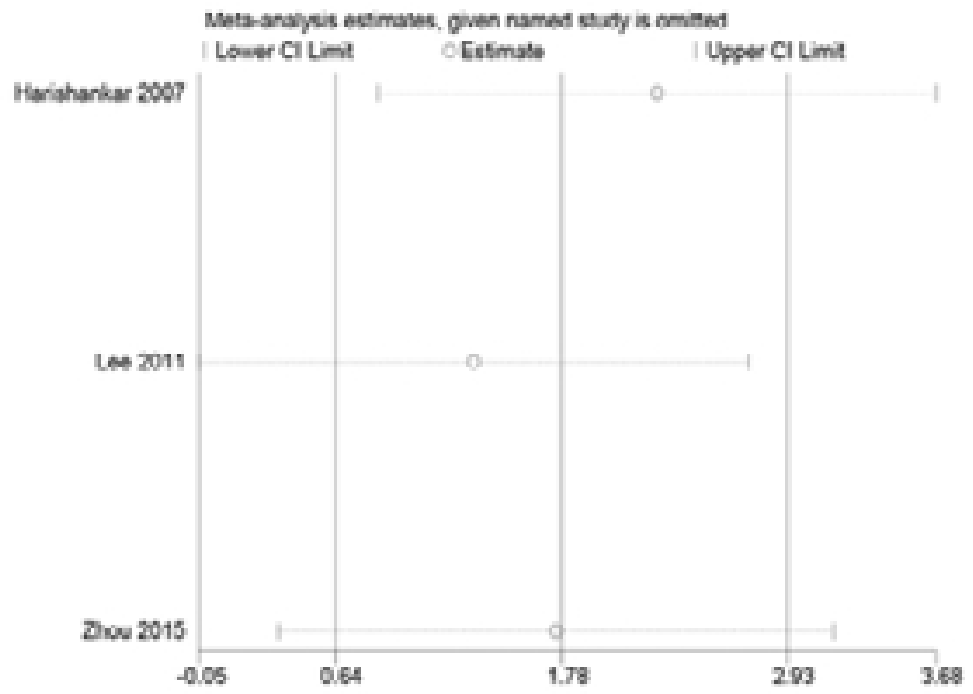

Figure 5: One-way sensitivity analysis of the pooled odds ratios and 95\% confidence interval for IL-18-137G >C polymorphism, omitting each dataset in the meta-analysis

Begg and Egger's tests were performed to assess the publication bias of included articles(Figure 6-9).The shapes of the funnel plots in all genetic models revealed no evi- $>0.05$ ). 


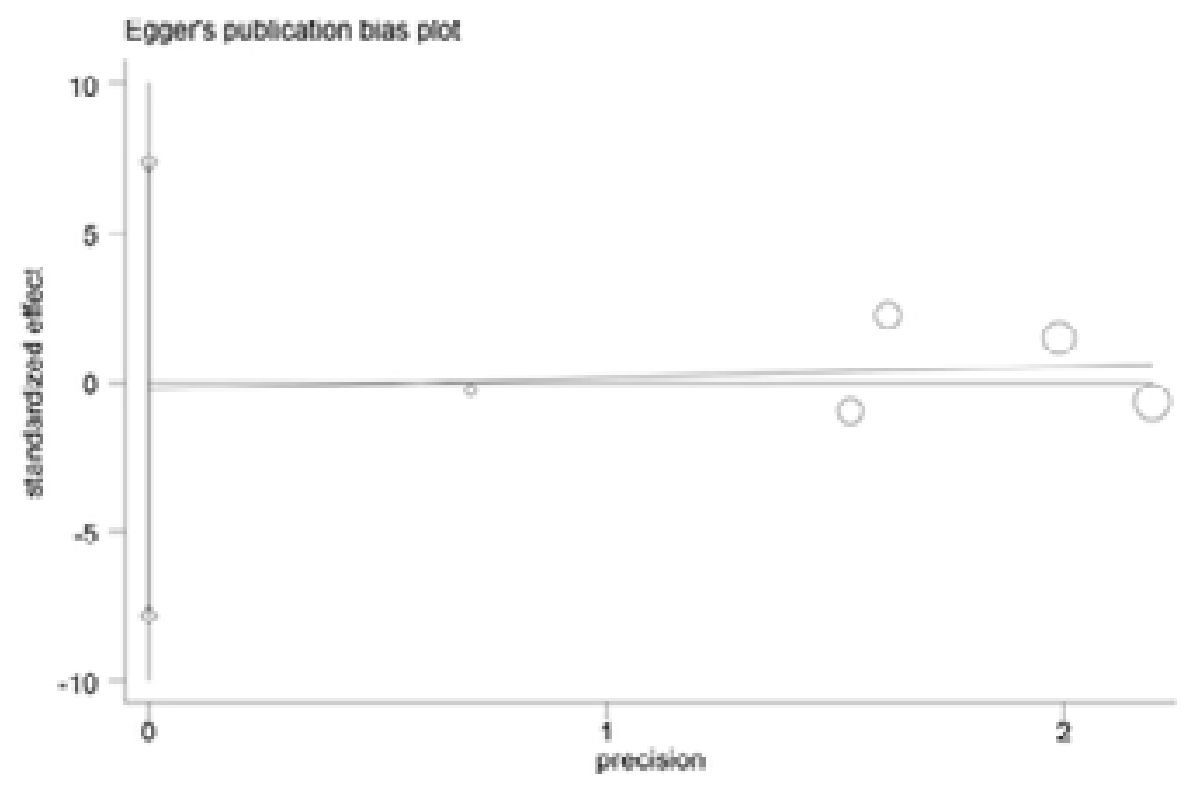

Figure 6: Egger's funnel plot analysis to detect potential publication bias for IL-18 -607C $>$ A polymorphism

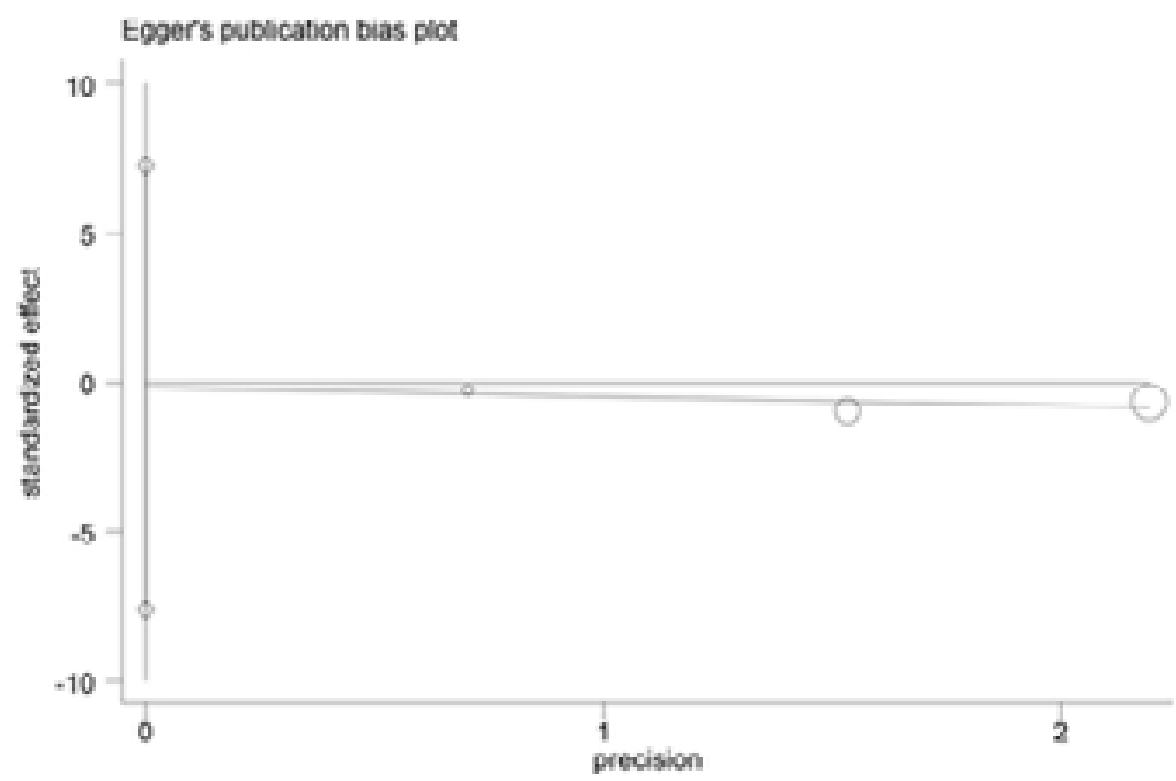

Figure 7: Egger's funnel plot analysis to detect potential publication bias for IL-18 -137G $>$ C polymorphism 


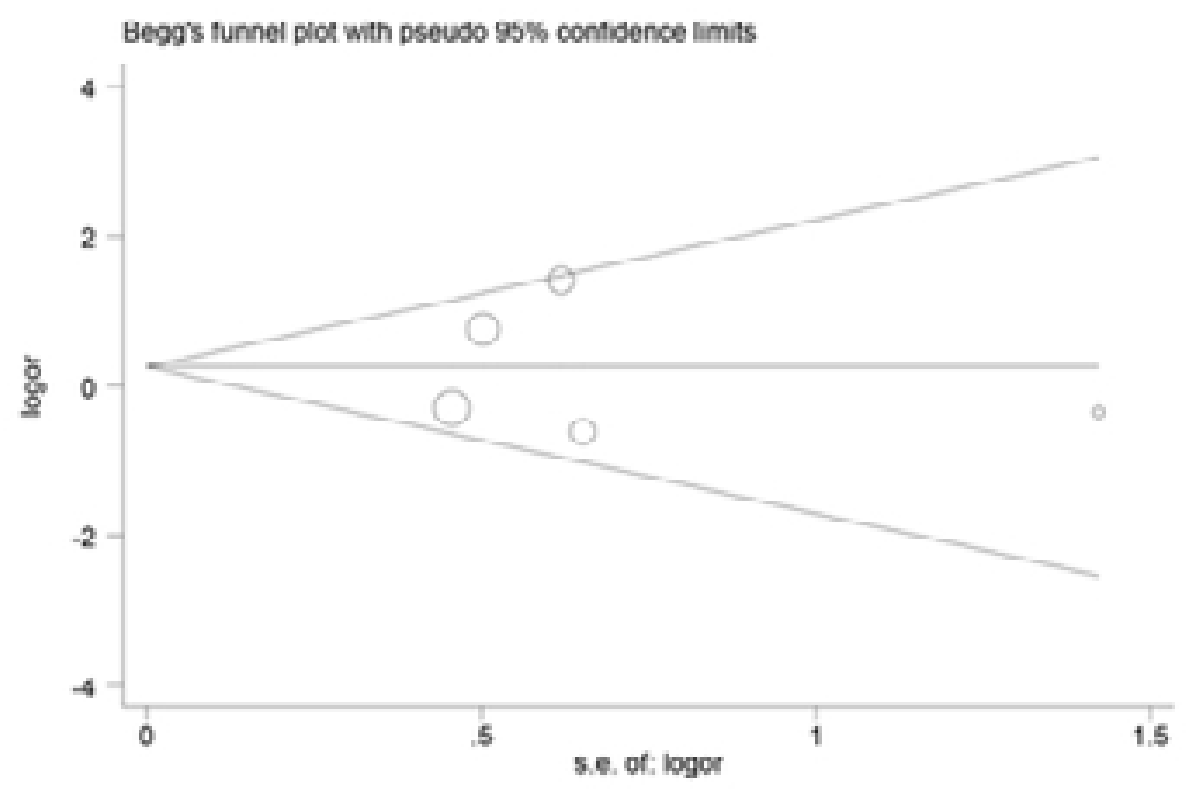

Figure 8: Begg's test to detect potential publication bias for IL-18 -607C > A polymorphism

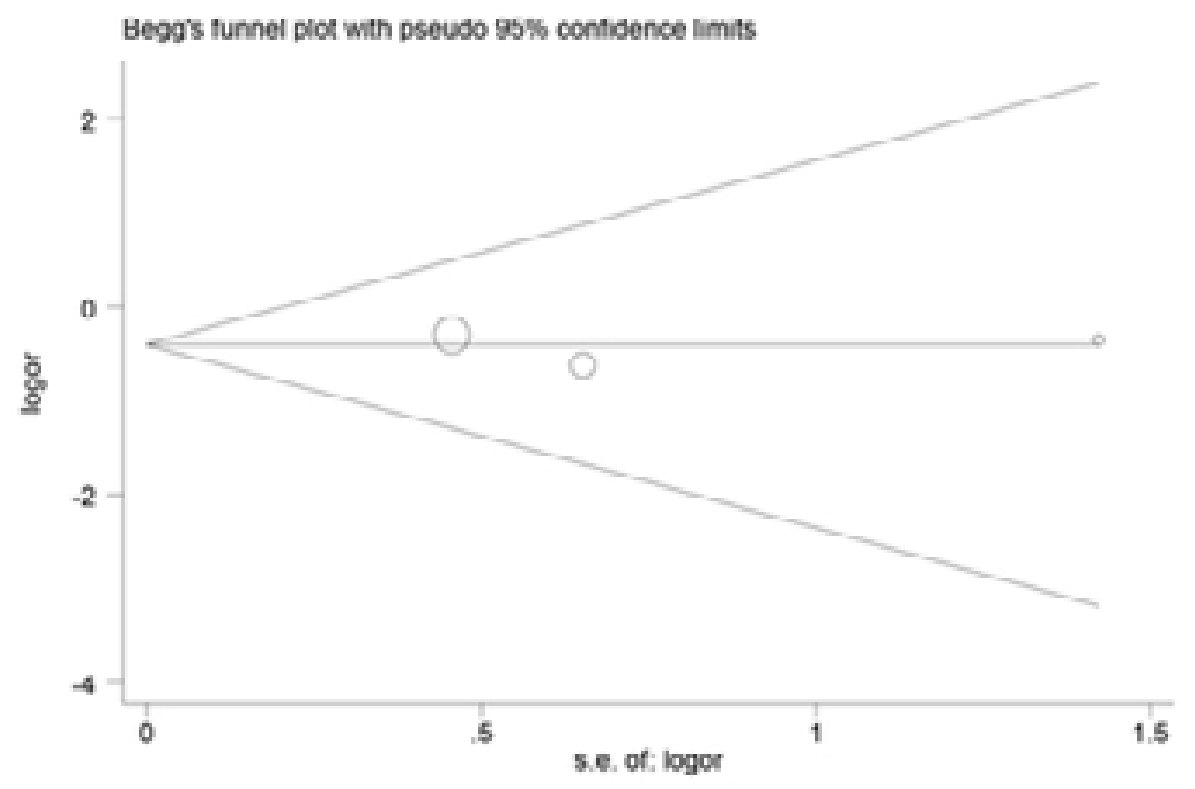

Figure 9: Begg's test to detect potential publication bias for IL-18 -137G $>$ C polymorphism.

\section{Discussion}

TB is a global public health problem that remains a huge burden throughout the world, although there has been an overall decline in TB incidence and mortality to this date. Accumulating evidence suggests that inflammatory cytokines play an important role in the pathogenesis of TB.
IL-18, belonging to the IL-1 superfamily, is a pleiotropic proinflammatory cytokine, which is involved in the regulation of both innate and acquired immune responses ${ }^{16}$. Concerning the effect of IL-18 polymorphisms on TB, contradictory results have obtained by previous studies. In the present study, we used meta-analysis to more accurately assess the impact of IL-18 SNPs on TB risk. 
To assess the role of IL-18 gene polymorphisms in susceptibility to $\mathrm{TB}$, we conducted a meta-analysis of 5 case-control studies, involving 1293 TB cases and 1724 healthy subjects. For the IL-18 -607C > A polymorphism, we found no association between this variant and TB susceptibility in the total population. Significant between-study heterogeneity was found among the three comparison models.Notably, after removing one article that deviated from HWE, the heterogeneity disappeared from stratification analysis.In addition, other factors including design diversity,sample sizes, and measurement errors may lead to heterogeneity. Because of the lack of relevant data,this factor requires further research in the future. For the IL-18 $-137 \mathrm{G}>\mathrm{C}$ polymorphism, no association was observed between the IL-18 $-137 \mathrm{G}>\mathrm{C}$ polymorphism and the risk of TB among all the genetic models.

\section{Limitations}

Some limitations of this meta-analysis should be acknowledged. First, this meta-analysis was based on a limited number of studies and the relatively small sample size, may reduce statistical power, especially for sub-group analysis. Second, due to the lack of detailed information such as lacking of subtyping of the TB in individual studies, we could not conduct further sub-group analysis to adjust for these possible confounding factors. Third, we only chose articles published electronically in two databases, and therefore some pertinent articles not included in these databases or unpublished articles with negative results may have been missed. Finally, gene-environment and gene-gene interactions were not considered in this study.

\section{Conclusion}

This meta-analysis suggested that there was no association between IL-18 polymorphisms and TB risk in the overall population. Considering the above-mentioned limitations, larger-scale and well-designed articles are required to further validate these findings and investigate an even wider range of associations in the future.

\section{Acknowledgements}

This work was supported by Natural Science Foundation of Zhejiang Province(LQ15H190001), Medicine and Health Science and Technology Projects of Zhejiang Province(2018KY141) and Hangzhou health science and technology projects(2013B14).

\section{Conflict of interest statement}

We declare that we have no conflict of interest.

\section{References}

1. Lv L, Li T, Xu K, Shi P, He B, Kong W, Wang J, Sun J.Sputum bacteriology conversion and treatment outcome of patients with multidrug-resistant tuberculosis. Infect Drug Resist. 2018;11:147-154 PubMed.

2. Zumla A, Raviglione M, Hafner R, von Reyn CF. Tuberculosis. N Engl J Med. 2013;368:745-755 PubMed.

3. Andrews JR, Noubary F, Walensky RP, Cerda R, Losina E, Horsburgh CR.Risk of progression to active tuberculosis following reinfection with Mycobacterium tuberculosis. Clin Infect Dis. 2012;54:784-791 PubMed.

4. Möller M, Hoal EG. Current findings, challenges and novel approaches in human genetic susceptibility to tuberculosis. Tuberculosis (Edinb) 2010;90:71-83. PubMed. 5. Yim JJ, Selvaraj P. Genetic susceptibility in tuberculosis. Respirology. 2010;15:241-256.

6. Laird SM, TuckermanEM, Li TC. Cytokine expression in the endometrium of women with implantation failure and recurrent miscarriage. Reprod Biomed Online. 2006; 13: 13-23.

7. Naik SR, Wala SM. Inflammation, allergy and asthma, complex immune origin diseases: mechanisms and therapeutic agents. Recent Pat Inflamm Allergy Drug Discov. 2013;7:62-95.

8. Caligiuri G, Kaveri S, Nicoletti A. When interleukin-18 conducts, the Preludio sounds the same no matter who plays. A rterioscler Thromb Vasc Biol. 2005; 25: 655-657.

9. Lee SH, Choi IH, Jeon YK, Park SJ, Lee HK, Lee YM, Chang CL, Kim YS, Lee MK, Park SK.Association between the interleukin-18 promoter polymorphism and pulmonary tuberculosis in a Korean population. Int J Tuberc Lung Dis. 2011;15:1246-1251.

10. Khripko OP, Sennikova NS, Lopatnikova JA, Khripko JI, Filipenko ML, Khrapov EA, Gelfgat EL, Yakushenko EV, Kozlov VA, Sennikov SV.Association of single nucleotide polymorphisms in the IL-18 gene with production of IL-18 protein by mononuclear cells from healthy donors. Mediators Inflamm. 2008; 2008:309721.

11. Harishankar M, Selvaraj P, Rajeswari DN, Anand SP, Narayanan PR.Promoter polymorphism of IL-18 gene in pulmonary tuberculosis in South Indian population. Int J Immunogenet. 2007;34:317-320. PubMed.

12. Han M, Yue J, Lian YY, Zhao YL, Wang HX, Liu LR.Relationship between single nucleotide polymorphism of interleukin-18 and susceptibility to pulmonary 
tuberculosis in the Chinese Han population. Microbiol Immunol. 2011;55:388-393. PubMed.

13. Lee SH, Choi IH, Jeon YK, Park SJ, Lee HK, Lee YM, et al.Association between the interleukin-18 promoter polymorphism and pulmonary tuberculosis in a Korean population. Int J Tuberc Lung Dis. 2011;15:1246-1251.

14. Taheri M, Hashemi-Shahri SM, Hamzehnejadi M, Naderi M, Moazeni-Roodi A, Bahari G,et al.Lack of association between interleukin-18 -607 C/A gene polymor- phism and pulmonary tuberculosis in Zahedan, Southeast Iran. Prague Med Rep. 2012;113:16-22. PubMed.

15. Zhou C, Ouyang N, Li QH, Luo SX, He Q, Lei H, et al.The $-137 \mathrm{G} / \mathrm{C}$ single nucleotide polymorphism in IL-18 gene promoter contributes to tuberculosis susceptibility in Chinese Han population. Infect Genet Evol. 2015;36:376380. PubMed.

16. Akira S.Innate immunity and adjuvants. Philos Trans R Soc Lond B Biol Sci. 2011;366:2748-2755. 